\title{
Modifiable Maternal Exposures and Offspring Blood Pressure: A Review of Epidemiological Studies of Maternal Age, Diet, and Smoking
}

\author{
MARIE-JO A. BRION, SAM D. LEARY, DEBBIE A. LAWLOR, GEORGE DAVEY SMITH, AND ANDY R. NESS
}

Department of Social Medicine [M.-J.A.B., D.A.L., G.D.S.], Centre for Causal Analyses in Translational Epidemiology (CAiTE) [D.A.L., G.D.S.], University of Bristol, Bristol BS8 2PR, United Kingdom; Department of Oral and Dental Science [S.D.L., A.R.N.], University of Bristol, Bristol BS1 2LY, United Kingdom

\begin{abstract}
Prenatal programming of adult disease is well established in animals. In humans the impact of common in utero exposures on long-term offspring health is less clear. We reviewed epidemiology studies of modifiable maternal exposures and offspring blood pressure (BP). Three maternal exposures were identified for review and meta-analyzed where possible: smoking during pregnancy, diet, and age at childbirth. Meta-analysis suggested there was a modest association between higher offspring BP and prenatal exposure to smoke (confounder-adjusted $\beta=0.62 \mathrm{~mm} \mathrm{Hg}, 95 \%$ confidence interval: $0.19-1.05, I^{2}=16.4 \%$ ). However, the level of confounder adjustment varied between studies, which in some studies attenuated the association to the null. There was no strong evidence that any component of maternal diet during pregnancy (maternal protein, energy, calcium, and various other nutrients) influences offspring BP. The results of studies of maternal age varied and there was strong evidence of heterogeneity in the pooled analysis. The association with maternal age, if present, was modest (confounderadjusted $\beta=0.09 \mathrm{~mm} \mathrm{Hg} / \mathrm{y}, 95 \%$ confidence interval: -0.03 to 0.21 , $I^{2}=89.8 \%$ ). In sum, there is little empirical evidence that the maternal exposures reviewed program offspring BP. Other components of offspring health may be more susceptible to effects of programming in utero. (Pediatr Res 63: 593-598, 2008)
\end{abstract}

$P^{\prime}$ rogramming has been defined as to the process by which a stimulus occurring during a sensitive period of development has lasting effects on development or risk of disease $(1,2)$. Evidence for programming is well established in animals (3) and exposures in humans, such as Rubella infection in utero (4) and inadequate periconceptual folate (5) can also result in structural changes (these might be described as teratogenic effects). However, the relevance of less extreme exposures in humans and their ability to induce adaptive responses is less clear.

Received October 16, 2007; accepted December 8, 2007.

Correspondence: Marie-Jo Brion, Ph.D., Department of Social Medicine, University of Bristol, Canynge Hall, Whiteladies Road, Bristol BS8 2 PR, UK; e-mail: mariejo.brion@bristol.ac.uk

Marie-Jo Brion is jointly funded by the Overseas Research Students Awards Scheme and the University of Bristol.

Supplemental material available online at www.pedresearch.org.
Interest in the role of early life and later chronic disease developed from early ecological studies by Forsdahl (6) linking infant mortality to subsequent cardiovascular disease mortality. Later studies by Barker and colleagues (1), showing that size at birth was related to adult chronic disease, extended this interest to intrauterine programming. Blood pressure (BP) is strongly and directly associated with mortality from cardiovascular disease (7), and the evidence for associations of low birth weight with adverse outcomes in later life is robust for BP (8) [although this has been disputed (9)]. In addition, there are strong cohort effects for secular changes in BP providing evidence for a role of early exposures $(10,11)$. Thus, we have focused on BP in this review.

There are various possible explanations for the association between low birth weight and later disease. These include confounding by socioeconomic position (SEP) (12), shared genes (13) and adjustment for later body size that represents programming in infancy or later in development (14). However, the association between birth weight and later disease may reflect in utero programming of adult disease; that is, exposures in utero resulting in lower birth weight via an impact on developing organs, structures and metabolic pathways with long-term consequences on risk of disease in later life.

The likely size of the modifiable effect of programming on later disease is unclear. Even extreme exposures such as famine (15) and maternal smoking during pregnancy (16) result in birth weight changes of only a few hundred grams. However, it is likely that birth weight is a marker for other exposures (e.g., fetal nutrition, genetic factors, epigenetic factors) (17) and thus one would expect weak or modest associations of birth weight with later health related outcomes, but associations with the "real" developmental exposures should be stronger. From a public health perspective it is important to determine whether modifiable exposures during developmental periods have important effects on later outcomes, such as BP. In this review we have moved beyond birth weight to

Abbreviations: BP, blood pressure; CI, confidence interval; RCT, randomized control trial; SBP, systolic blood pressure; SEP, socioeconomic position 


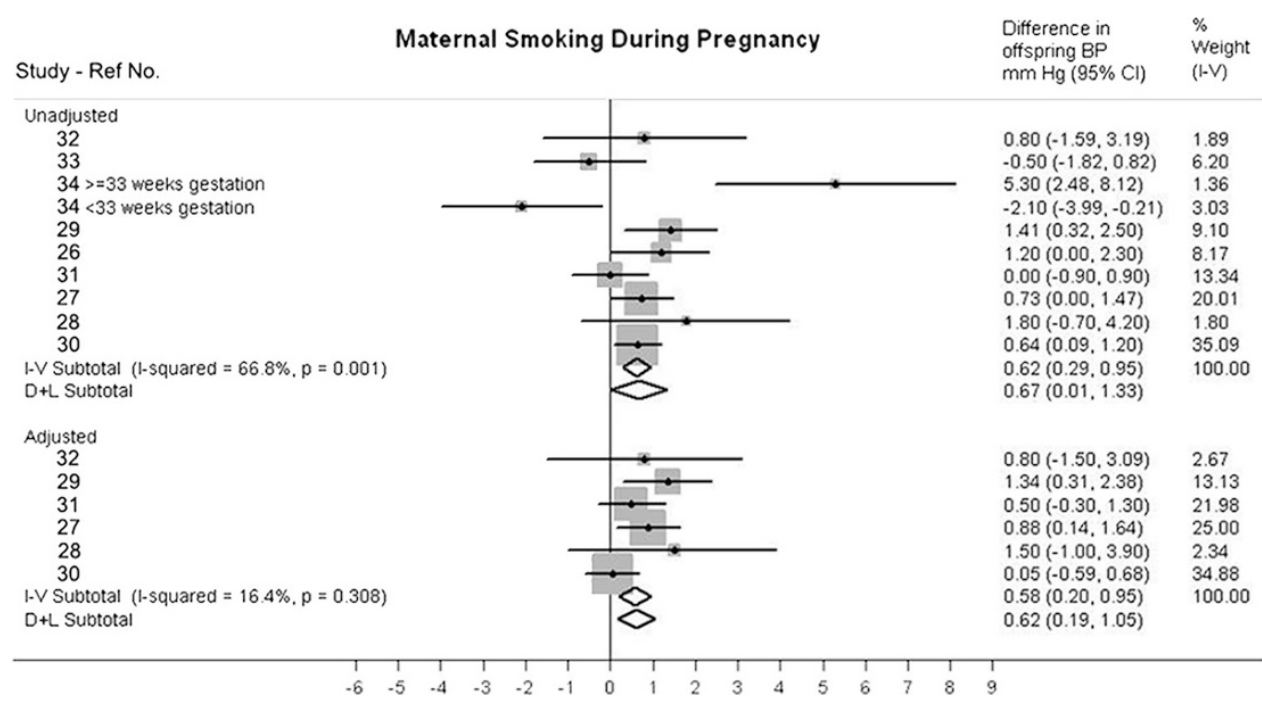

Figure 1. I-V: fixed effects, D + L: random effects.

consider epidemiologic evidence that exposures in pregnancy can influence later offspring BP.

We included maternal behaviors that might program subsequent offspring blood pressure in this review if the exposures:

- occur during gestation

- are modifiable

- are common (thus modification will be of public health importance).

Although we acknowledge that programming during development can include the postnatal period we have focused on prenatal factors. We identified three behaviors for inclusion in this review: maternal diet, smoking, and maternal age. Other maternal characteristics such as maternal anemia, obesity, gestational diabetes, and hypertension, were not included in this review as these are determined by genetic and environmental factors, and thus were not considered modifiable maternal behaviors. We considered differences of $1 \mathrm{~mm} \mathrm{Hg}$ or higher to be of public health importance.

We carried out a systematic search using terms relating to maternal exposure, maternal-fetal exchange, maternal nutrition, prenatal exposure delayed affects, prenatal nutrition, maternal smoking, maternal age, and BP (search strategy available on request). We included studies with 1) sample size $>100,2$ ) outcomes in adults or children $>1 \mathrm{y}$, and 3) individual level data (data abstraction performed by M.J.B.).

Where possible, data from different studies were pooled using meta-analysis (STATA version 9). $\beta$ coefficients and 95\% confidence intervals (CI) from regression models were entered into STATA. If studies only reported group means and standard errors, the $\beta$ and $95 \%$ CI were calculated manually (calculations performed by M.J.B.). Estimates from both fixed- and random-effects models are presented. Randomeffects models are preferable when combining heterogeneous studies. However, if the heterogeneity is due to publication bias then fixed-effects models are preferable as they give less weight to smaller studies (18). Heterogeneity was assessed using Higgins' $I^{2}$ statistic, which is the proportion of total variation in study estimates that is due to between study differences in effect (19).

\section{Maternal Smoking During Pregnancy}

Maternal cigarette smoking during pregnancy is associated with low birth weight and premature birth $(20,21)$. Additionally, prenatal exposure to nicotine alters kidney weight and BP in genetically susceptible mice (22). In humans, maternal smoking may influence offspring BP via adverse effects on the fetal and uteroplacental vasculature $(23,24)$. Adverse cardiovascular adaptions can occur as a result of the prolonged hypoxia that fetuses of women who smoke during pregnancy are exposed to (25).

We identified nine observational studies assessing the association between maternal prenatal smoking and offspring BP in children (Table; supplementary data available online). Results were mixed, with positive associations (26-29), null associations (30-33) and interactions with gestational age (34) each reported (Fig. 1). Adjustment for a comprehensive range of indicators of SEP was found in one study to abolish the association between maternal smoking and offspring BP (30). This evidence of the key role of confounding by social and familial factors is further supported by the similarity of maternal smoking and paternal smoking associations, suggesting an absence of intrauterine effects as maternal smoking associations would be expected to be much larger than paternal smoking associations even if paternal smoke reflected exposure to second-hand smoke (30).

Data were pooled and are presented separately for unadjusted and fully adjusted estimates (Fig. 1). Despite betweenstudy heterogeneity among unadjusted studies, pooled effect sizes were similar in random- and fixed-effect models. Maternal prenatal smoking was associated with a modest increase in offspring BP (0.67 mm Hg unadjusted, $0.62 \mathrm{~mm} \mathrm{Hg}$ adjusted, random effects model). The heterogeneity in the unadjusted meta-analysis $\left(I^{2}=67 \%\right)$ was largely attributable to one study of preterm and term infants. This study was relatively small; 


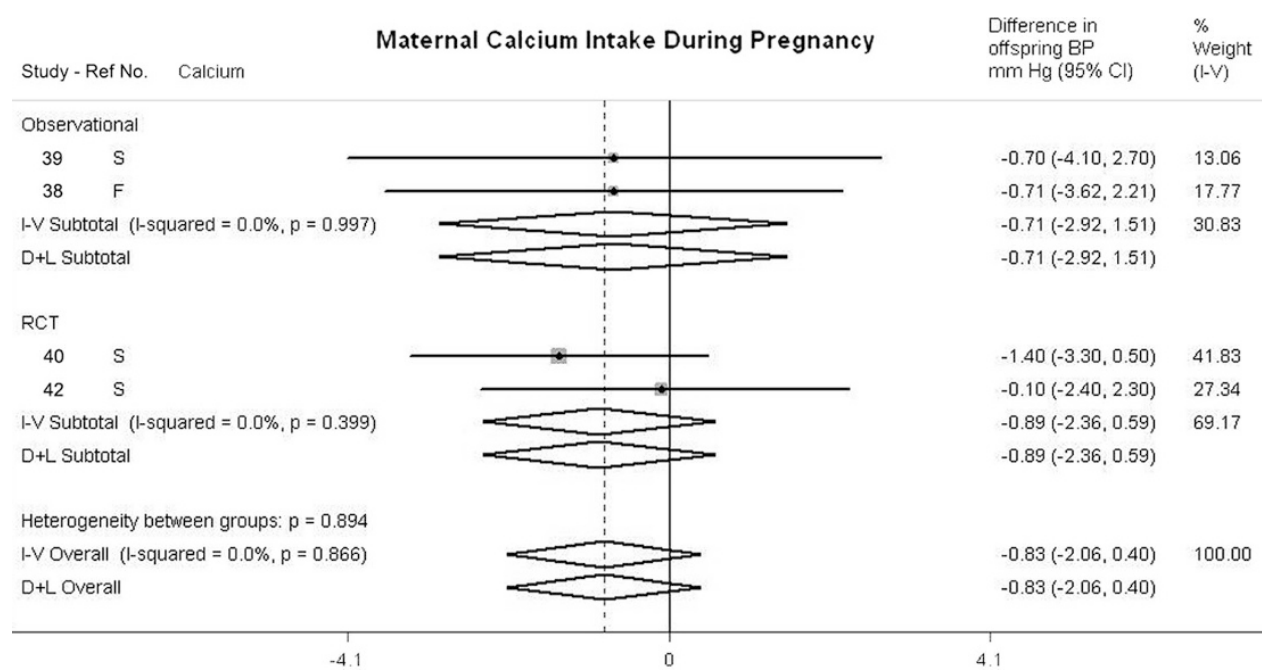

Figure 2. I-V: fixed-effects, D + L: random-effects. RCT, randomized controlled trial; Obs, observational study; S, calcium supplements; F, calcium from food. To correspond with the level of calcium in supplements, the difference for calcium from food was based on calculation of $2 \mathrm{~g}$ difference in food based calcium.

therefore, its removal from the meta-analysis did not substantively alter the overall pooled estimates $(\beta=0.64,95 \% \mathrm{CI}$ : $0.30-0.98$ for random effects model, $I^{2}=18.3 \%$ ). Despite the likelihood of confounding, pooled estimates for unadjusted and adjusted effects were not substantively different. In studies providing both unadjusted and adjusted estimates the pooled effect size only decreased from $0.67 \mathrm{~mm} \mathrm{Hg}$ (95\% CI: $0.31-$ 1.04) to $0.62 \mathrm{~mm} \mathrm{Hg}$ (95\% CI: $0.19-1.05$, random effects for both). However, the potential confounding factors taken into account for different studies varied between studies.

In summary, there is some evidence that maternal smoking in pregnancy is associated with higher offspring BP in childhood. The association is small but present in both unadjusted and adjusted results. However, one study that compared associations of maternal and paternal smoking with offspring BP suggests the association is not due to intrauterine programming but is most likely explained by confounding due to shared familial and environmental factors.

\section{Maternal Diet}

Exposure to famine in utero has been associated with reduced birth weight (15) and prenatal dietary supplementation in developing countries increases offspring birth weight (35). Prenatal exposure to low-protein diets produces elevated systolic blood pressure (SBP) in offspring of rats (36). The programming of offspring BP by maternal under nutrition is believed to occur via effects on kidney structure and function (37).

Seven studies were identified assessing maternal prenatal diet and offspring BP. Five studies assessed prenatal calcium intake (38-42), five studies assessed protein and energy/ carbohydrates $(38,41,43-45)$, and four studies reported on various other micro and macronutrients $(38,41,43,44)$.

Calcium. In humans, maternal calcium supplementation lowers the risk of high BP in pregnancy (46), which is associated with maternal death, prenatal complications and neonatal mortality (47). In animals, prenatal diets deficient in calcium are associated with higher offspring BP (48). It is possible that prenatal programming may occur through effects on calcium-regulating hormones (49).

We identified five studies of maternal calcium intake and offspring BP, all assessing BP in children. There were three observational studies $(38,39,41)$ and two randomized control trials [RCTs $(40,42)]$. In the observational studies, maternal calcium intake from foods (38), supplements (39), or both (41) was not associated with offspring BP. In the RCTs, there were no main effects of calcium supplementation in an Australian study; however, in the other RCT of Argentinean mothers, maternal calcium supplementation was associated with a reduction in offspring SBP at $7 \mathrm{y}$ of $1.4 \mathrm{~mm} \mathrm{Hg}$, although evidence for this effect was not strong (95\% CI: -3.2 to 0.5 ) (40). This study also reported an interaction between calcium supplementation and child body mass index (BMI), which was not replicated in observational studies $(38,39)$.

Meta-analysis was carried out on the four studies that provided data (Fig. 2). There was some evidence of an association between higher maternal calcium intake in pregnancy and lower offspring BP. However, the pooled estimate was modest and the confidence interval included the null, suggesting that the possibility of no association between maternal calcium intake and offspring BP cannot be excluded.

Associations with calcium intake could be difficult to assess as differences in physiologic effects of calcium may occur between supplement-derived and food-derived calcium (50). Furthermore, calcium intake from foods may also be more difficult to estimate precisely compared with calcium in supplements. Thus, associations with food-derived calcium may be more difficult to detect. Associations could also vary among countries with differing nutritional status where there may be pronounced differences in diet and health.

In summary, maternal calcium intake may have small effects on offspring BP, however, evidence for this association is not strong and the possibility of no effect of maternal calcium intake on offspring BP cannot be ruled out. Suggestions for increasing precision of estimates include improved accuracy in assessing calcium intake and distinguishing effects 


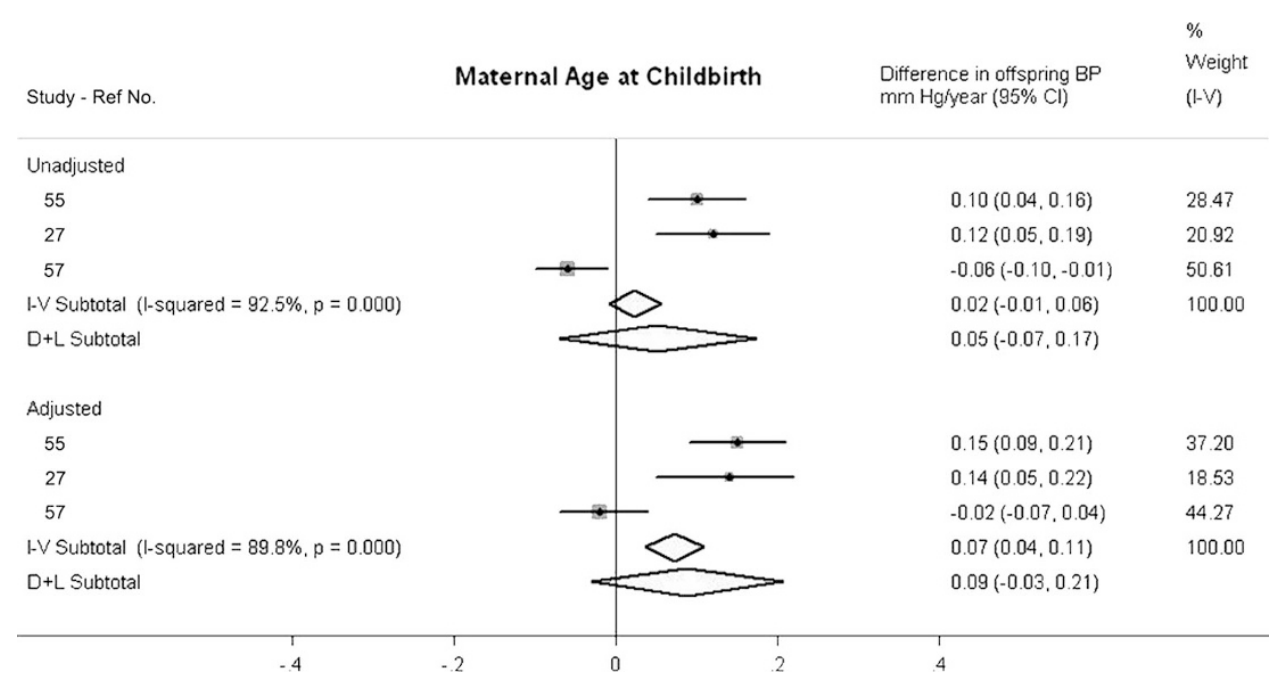

Figure 3. I-V: fixed-effects, D + L: random-effects.

of: 1) supplements versus food-derived calcium, and 2) calcium in poorly nourished versus well-nourished populations.

Protein and carbohydrate. We identified five studies of maternal prenatal protein and carbohydrate intake. There were four observational studies, in British children (38), Philipino adolescents (43), and Scottish adults $(41,44)$. There was one cluster RCT in Guatemalan young adults (45).

No main effects of maternal protein intake were reported in two observational studies $(38,41)$ or the RCT $(45)$. High maternal protein intake was associated with lower offspring BP in Philipino boys (43) and higher offspring BP in Scottish adults (44). Other high protein foods in the latter study (milk, eggs, cheese) were not associated with offspring BP. Complex interactions with high and low protein intake were reported in one study (41) but these were not confirmed elsewhere (38).

Similar to the findings with protein intake, there were also no main effects of maternal carbohydrate intake in two observational studies $(41,43)$ or the RCT $(45)$. Although one study reported an association between low maternal carbohydrate intake and higher offspring BP (44), another reported an association in the opposite direction (in fully-adjusted analyses) (38).

We believed it was inappropriate to formally combine results from these studies as they were on very different measurement scales. In some cases, it is possible to convert results from studies using different units onto a common scale; however, there was insufficient information from the studies reviewed to attempt this with confidence. Without metaanalysis, it is more difficult to assess the overall effect size, its importance, and any heterogeneity of results. That said, results of studies of maternal protein and carbohydrate intake during pregnancy seem to be inconsistent, with little evidence that maternal protein or carbohydrate intake have important effects on offspring BP.

Other dietary components. A variety of other dietary constituents have also been assessed. Weak evidence $(p=0.09)$ for an association between higher maternal consumption of green vegetables during pregnancy and reduced offspring BP was reported in one study (44). No associations were reported for a variety of maternal nutrients including fat, calcium, vitamin $\mathrm{A}$, thiamine, riboflavin, niacin, and vitamin $\mathrm{C}$ in one study (41) and fats (total, saturated, polyunsaturated, monounsaturated, Omega 3), potassium and magnesium in another study (38). Maternal fat intake was associated with reduced BP in Philipino girls but not in boys (43).

\section{Maternal Age}

Both advanced maternal age (51) and young maternal age (52) have been associated with a adverse perinatal outcomes, like complications at delivery and low neonatal birth weight. However, it is not clear what effect maternal age has on the long-term offspring health and through which mechanisms. For advanced maternal age, age-related modification of reproductive organs, placental function and hormonal activity in mothers have each been proposed as having possible programming effects (53). For younger (teenage) mothers, an imbalance between competing nutritional needs of the mother and offspring may result in adverse effects on the developing fetus which program later health (54).

Four observational studies were identified, all assessing BP in children. Two studies reported positive associations between maternal age and offspring BP $(27,55)$. A third reported differing effects for female and male offspring (56) and the fourth study reported an inverse association between maternal age at childbirth and offspring BP that disappeared after adjusting for confounders (57).

We were able to pool data for three studies (Fig. 3). There was considerable heterogeneity among studies with the $I^{2}$ statistic indicating that $92.5 \%$ (unadjusted) and $89.8 \%$ (adjusted) of the variation was attributable to between-study differences. Thus, we focus on random-effect estimates. In both unadjusted and adjusted meta-analyses, there was little evidence of an association between maternal age at childbirth and offspring BP.

Differences in effects of maternal age could vary in relation to population characteristics of different countries or because reasons for early or delayed childbearing may have changed 
over time. Additionally, varying confounder adjustment was carried out among studies ranging from no adjustment to extensive adjustment.

In summary, there was strong evidence of heterogeneity among studies of maternal age. Although this makes it difficult to arrive at a precise pooled estimate, effects of maternal age on offspring BP, if any at all, are likely to be small.

\section{CONCLUSION}

We found limited evidence for substantial effects on programming of BP in humans by maternal prenatal behaviors, specifically, by maternal smoking, prenatal diet, and maternal age at childbirth. Furthermore, of studies reporting prenatal influences, observed effect sizes have been modest $(<1 \mathrm{~mm}$ $\mathrm{Hg}$ ) suggesting that associations, if causal, would be of limited public health importance.

There are various possible reasons for the lack of evidence for the programming of BP by the maternal behaviors reviewed here. It may be that BP is not, in fact, programmed in utero by these behaviors and perhaps evidence for early life associations reflects programming in postnatal life, for example in relation to early growth, breast feeding and infant diet (17). The lack of evidence could also be due to poor measures of exposure. Although this could be true for maternal diet, it is unlikely that imprecise assessment would account for the lack of observed effects of maternal smoking, prenatal supplementation or maternal age. The absence of clear associations could also be due to over adjustment. However, even in unadjusted models only modest effects (if any) were observed.

It is possible that the range of exposures assessed in the studies reviewed may have been limited. The original studies of individuals born in the 1920s and 1930s may not be comparable with contemporary well-nourished populations and the studies reviewed were mostly of Western populations born in the 1970s to 1990 s. Associations may also differ in relation to countries with poorer economic development. Furthermore, with respect to the issue of limited exposures, while the maternal behaviors considered in this review may not program offspring BP, other exposures not included in this review (e.g., gestational diabetes and hypertension, maternal anemia, prenatal physical activity, alcohol intake, or psychological stress) may have important effects.

Finally, it is possible that the limited evidence for in utero programming of BP by maternal diet, smoking, and age is due to the age at which BP was measured in offspring in the studies reviewed. Almost all studies reported on offspring BP in children. Thus, although associations were not consistently detected at this age, it is possible that effects of programming by modifiable maternal behaviors may be evident for BP in adults. Alternatively, effects of in utero programming by maternal behaviors may be more consistently detected at ages earlier than in childhood, such as in infants and neonates. Maternal smoking during pregnancy $(58,59)$ and advanced maternal age (60) have both been associated with greater BP in neonates and there is some evidence that maternal calcium supplementation is associated with lower BP in infants $(50,61,62)$. However, if such exposures are subsequently un- related to later BP, they may have limited implications for adult cardiovascular risk.

Although there is limited evidence of in utero programming of BP in children by modifiable maternal behaviors, evidence of programming may be more robust in relation to other components of offspring health, for example insulin resistance (63). Maternal diet in pregnancy has also been linked to other outcomes such as offspring neurocognitive function (64) and adverse changes in tissue physiology, DNA methylation, and gene expression (65).

To improve our understanding of the extent of programming in humans, future epidemiologic studies of programming will need to incorporate exposures and outcome measures that are consistent with animal and other laboratory studies. Further studies in developing countries could also provide better opportunities to study to what extent programming occurs in humans. Additionally, follow-up studies of RCTs would improve the quality of the evidence for or against the existence of programming in humans. The use of maternal and paternal associations (30) also provides a method of separating intrauterine effects from associations related to familial or environmental factors. Stronger associations of offspring health with maternal exposures suggest possible intrauterine effects whereas similar associations of offspring health with maternal and paternal exposures suggest that common factors related to the family or environment are likely to drive the association. Finally, the use of Mendelian randomization could be a useful method for exploring causality in relation to associations of prenatal factors and later offspring health (66). For example, maternal lactase persistence genotype can serve as an instrumental variable for milk drinking behavior. These maternal genotypes may subsequently be used as an unconfounded measure of lactose-containing foods and can be used to explore causal associations with offspring health (67).

In conclusion, at present there is little empirical evidence that modifiable maternal behaviors, such as maternal diet, smoking during pregnancy, and maternal age at childbirth, program offspring BP.

Acknowledgment. We thank Ross Harris for his help with the meta-analyses.

\section{REFERENCES}

1. Barker DJ 1998 Mothers, Babies, and Health in Later Life. Churchill Livingstone, Edinburgh

2. Lucas A 1991 Programming by early nutrition in man. In: Bock GR, Whelan J (eds) The Childhood Environment and Adult Disease. Wiley, Chichester, pp 38-55

3. Lucas A 1998 Programming by early nutrition: an experimental approach. J Nutr 128:401S-406S

4. De Santis M, Cavaliere AF, Straface G, Caruso A 2006 Rubella infection in pregnancy. Reprod Toxicol 21:390-398

5. Lumley J, Watson L, Watson M, Bower C 2001 Periconceptional supplementation with folate and/or multivitamins for preventing neural tube defects. Cochrane Database Syst Rev: CD001056

6. Forsdahl A 1977 Are poor living conditions in childhood and adolescence an important risk factor for arteriosclerotic heart disease? Br J Prev Soc Med 31:91-95

7. Lewington S, Clarke R, Qizilbash N, Peto R, Collins R 2002 Age-specific relevance of usual blood pressure to vascular mortality: a meta-analysis of individual data for one million adults in 61 prospective studies. Lancet 360:1903-1913

8. Davies AA, Davey Smith G, May MT, Ben-Shlomo Y 2006 Association between birth weight and blood pressure is robust, amplifies with age, and may be underestimated. Hypertension 48:431-436 
9. Huxley R, Neil A, Collins R 2002 Unravelling the fetal origins hypothesis: is there really an inverse association between birthweight and subsequent blood pressure? Lancet 360:659-665

10. McCarron P, Okasha M, McEwen J, Smith GD 2001 Changes in blood pressure among students attending Glasgow University between 1948 and 1968: analyses of cross sectional surveys. BMJ 322:885-889

11. McCarron P, Davey Smith G, Okasha M 2002 Secular changes in blood pressure in childhood, adolescence and young adulthood: systematic review of trends from 1948 to 1998. J Hum Hypertens 16:677-689

12. Peters TJ, Golding J, Butler NR, Fryer JG, Lawrence CJ, Chamberlain GV 1983 Plus ca change: predictors of birthweight in two national studies. Br J Obstet Gynaecol 90:1040-1045

13. Hattersley AT, Beards F, Ballantyne E, Appleton M, Harvey R, Ellard S 1998 Mutations in the glucokinase gene of the fetus result in reduced birth weight. Nat Genet 19:268-270

14. Lucas A, Fewtrell MS, Cole TJ 1999 Fetal origins of adult disease-the hypothesis revisited. BMJ 319:245-249

15. Lumey LH, Ravelli AC, Wiessing LG, Koppe JG, Treffers PE, Stein ZA 1993 The Dutch famine birth cohort study: design, validation of exposure, and selected characteristics of subjects after 43 years follow-up. Paediatr Perinat Epidemiol $7: 354-367$

16. Hindmarsh PC, Geary MP, Rodeck CH, Kingdom JC, Cole TJ 2002 Intrauterine growth and its relationship to size and shape at birth. Pediatr Res 52:263-268

17. Lawlor DA, Davey Smith G 2005 Early life determinants of adult blood pressure. Curr Opin Nephrol Hypertens 14:259-264

18. Sterne JA, Egger M, Smith GD 2001 Systematic reviews in health care: Investigating and dealing with publication and other biases in meta-analysis. BMJ 323:101-105

19. Higgins JP, Thompson SG, Deeks JJ, Altman DG 2003 Measuring inconsistency in meta-analyses. BMJ 327:557-560

20. Andres RL, Day MC 2000 Perinatal complications associated with maternal tobacco use. Semin Neonatol 5:231-241

21. Bernstein IM, Mongeon JA, Badger GJ, Solomon L, Heil SH, Higgins ST 2005 Maternal smoking and its association with birth weight. Obstet Gynecol 106:986991

22. Pausova Z, Paus T, Sedova L, Berube J 2003 Prenatal exposure to nicotine modifies kidney weight and blood pressure in genetically susceptible rats: a case of geneenvironment interaction. Kidney Int 64:829-835

23. Andersen MR, Walker LR, Stender S 2004 Reduced endothelial nitric oxide synthase activity and concentration in fetal umbilical veins from maternal cigarette smokers. Am J Obstet Gynecol 191:346-351

24. Matturri L, Lavezzi AM, Ottaviani G, Rossi L 2003 Intimal preatherosclerotic thickening of the coronary arteries in human fetuses of smoker mothers. J Thromb Haemost 1:2234-2238

25. Zhang L 2005 Prenatal hypoxia and cardiac programming. J Soc Gynecol Investig $12: 2-13$

26. Blake KV, Gurrin LC, Evans SF, Beilin LJ, Landau LI, Stanley FJ, Newnham JP 2000 Maternal cigarette smoking during pregnancy, low birth weight and subsequent blood pressure in early childhood. Early Hum Dev 57:137-147

27. Lawlor DA, Najman JM, Sterne J, Williams GM, Ebrahim S, Davey Smith G 2004 Associations of parental, birth, and early life characteristics with systolic blood pressure at 5 years of age: findings from the Mater-University study of pregnancy and its outcomes. Circulation 110:2417-2423

28. Oken E, Huh SY, Taveras EM, Rich-Edwards JW, Gillman MW 2005 Associations of maternal prenatal smoking with child adiposity and blood pressure. Obes Res 13:2021-2028

29. Williams S, Poulton R 1999 Twins and maternal smoking: ordeals for the fetal origins hypothesis? A cohort study. BMJ 318:897-900

30. Brion MJ, Leary SD, Smith GD, Ness AR 2007 Similar associations of parental prenatal smoking suggest child blood pressure is not influenced by intrauterine effects. Hypertension 49:1422-1428

31. Bergel E, Haelterman E, Belizan J, Villar J, Carroli G 2000 Perinatal factor associated with blood pressure during childhood. Am J Epidemiol 151:594-60

32. Law CM, Barker DJ, Bull AR, Osmond C 1991 Maternal and fetal influences on blood pressure. Arch Dis Child 66:1291-1295

33. Whincup PH, Cook DG, Papacosta O 1992 Do maternal and intrauterine factors influence blood pressure in childhood? Arch Dis Child 67:1423-1429

34. Morley R, Leeson PC, Lister G, Lucas A 1995 Maternal smoking and blood pressure in 7.5 to 8 year old offspring. Arch Dis Child 72:120-124

35. Osrin D, Vaidya A, Shrestha Y, Baniya RB, Manandhar DS, Adhikari RK, Filteau S, Tomkins A, Costello AM 2005 Effects of antenatal multiple micronutrient supplementation on birthweight and gestational duration in Nepal: double-blind, randomised controlled trial. Lancet 365:955-962

36. McMillen IC, Robinson JS 2005 Developmental origins of the metabolic syndrome: prediction, plasticity, and programming. Physiol Rev 85:571-633

37. Hughson M, Farris AB III, Douglas-Denton R, Hoy WE, Bertram JF 2003 Glomerular number and size in autopsy kidneys: the relationship to birth weight. Kidney Int 63:2113-2122

38. Leary SD, Ness AR, Emmett PM, Davey Smith G, Headley JE 2005 Maternal diet in pregnancy and offspring blood pressure. Arch Dis Child 90:492-493
39. Morley R, Carlin JB, Dwyer T 2004 Maternal calcium supplementation and cardiovascular risk factors in twin offspring. Int J Epidemiol 33:1304-1309

40. Belizan JM, Villar J, Bergel E, del Pino A, Di Fulvio S, Galliano SV, Kattan C 1997 Long-term effect of calcium supplementation during pregnancy on the blood pressure of offspring: follow up of a randomised controlled trial. BMJ 315:281-285

41. Campbell DM, Hall MH, Barker DJ, Cross J, Shiell AW, Godfrey KM 1996 Diet in pregnancy and the offspring's blood pressure 40 years later. Br J Obstet Gynaecol 103:273-280

42. Hiller JE, Crowther CA, Moore VA, Willson K, Robinson JS 2007 Calcium supplementation in pregnancy and its impact on blood pressure in children and women: follow up of a randomised controlled trial. Aust N Z J Obstet Gynaecol 47:115-121

43. Adair LS, Kuzawa CW, Borja J 2001 Maternal energy stores and diet composition during pregnancy program adolescent blood pressure. Circulation 104:1034-1039

44. Shiell AW, Campbell-Brown M, Haselden S, Robinson S, Godfrey KM, Barker DJ 2001 High-meat, low-carbohydrate diet in pregnancy: relation to adult blood pressure in the offspring. Hypertension 38:1282-1288

45. Webb AL, Conlisk AJ, Barnhart HX, Martorell R, Grajeda R, Stein AD 2005 Maternal and childhood nutrition and later blood pressure levels in young Guatemalan adults. Int J Epidemiol 34:898-904

46. Hofmeyr GJ, Atallah AN, Duley L 2006 Calcium supplementation during pregnancy for preventing hypertensive disorders and related problems. Cochrane Database Syst Rev 3:CD001059

47. Douglas KA, Redman CW 1994 Eclampsia in the United Kingdom. BMJ 309:13951400

48. Bergel E, Belizan JM 2002 A deficient maternal calcium intake during pregnancy increases blood pressure of the offspring in adult rats. BJOG 109:540-545

49. Arden NK, Major P, Poole JR, Keen RW, Vaja S, Swaminathan R, Cooper C, Spector TD 2002 Size at birth, adult intestinal calcium absorption and 1,25(OH)(2) vitamin D. QJM 95:15-21

50. Gillman MW, Rifas-Shiman SL, Kleinman KP, Rich-Edwards JW, Lipshultz SE 2004 Maternal calcium intake and offspring blood pressure. Circulation 110:19901995

51. Yuan W, Steffensen FH, Nielsen GL, Moller M, Olsen J, Sorensen HT 2000 A population-based cohort study of birth and neonatal outcome in older primipara. Int J Gynaecol Obstet 68:113-118

52. Scholl TO, Hediger ML, Schall JI 1997 Maternal growth and fetal growth: pregnancy course and outcome in the Camden Study. Ann N Y Acad Sci 817:292-301

53. Bottini E, Meloni GF, MacMurray J, Ammendola M, Meloni T, Gloria-Bottini G 2001 Maternal age and traits of offspring in humans. Placenta 22:787-789

54. Scholl TO, Hediger ML, Schall JI, Khoo CS, Fischer RL 1994 Maternal growth during pregnancy and the competition for nutrients. Am J Clin Nutr 60:183-188

55. Whincup PH, Cook DG, Shaper AG 1989 Early influences on blood pressure: a study of children aged 5-7 years. BMJ 299:587-591

56. Higgins M, Keller J, Moore F, Ostrander L, Metzner H, Stock L 1980 Studies of blood pressure in Tecumseh, Michigan. I. Blood pressure in young people and its relationship to personal and familial characteristics and complications of pregnancy in mothers. Am J Epidemiol 111:142-155

57. Roberts RJ, Leary SD, Smith GD, Ness AR 2005 Maternal age in pregnancy and offspring blood pressure in childhood in the Avon Longitudinal Study of Parents and Children (ALSPAC). J Hum Hypertens 19:893-900

58. Beratis NG, Panagoulias D, Varvarigou A 1996 Increased blood pressure in neonate and infants whose mothers smoked during pregnancy. J Pediatr 128:806-812

59. O'Sullivan MJ, Kearney PJ, Crowley MJ 1996 The influence of some perinatal variables on neonatal blood pressure. Acta Paediatr 85:849-853

60. Gillman MW, Rich-Edwards JW, Rifas-Shiman SL, Lieberman ES, Kleinman KP, Lipshultz SE 2004 Maternal age and other predictors of newborn blood pressure. J Pediatr 144:240-245

61. Hatton DC, Harrison-Hohner J, Coste S, Reller M, McCarron D 2003 Gestationa calcium supplementation and blood pressure in the offspring. Am J Hypertens 16:801-805

62. McGarvey ST, Zinner SH, Willett WC, Rosner B 1991 Maternal prenatal dietary potassium, calcium, magnesium, and infant blood pressure. Hypertension 17:218224

63. Ravelli AC, van der Meulen JH, Michels RP, Osmond C, Barker DJ, Hales CN, Bleker OP 1998 Glucose tolerance in adults after prenatal exposure to famine. Lancet 351:173-177

64. Hibbeln JR, Davis JM, Steer C, Emmett P, Rogers I, Williams C, Golding J 2007 Maternal seafood consumption in pregnancy and neurodevelopmental outcomes in childhood (ALSPAC study): an observational cohort study. Lancet 369:578-585

65. Langley-Evans SC 2006 Developmental programming of health and disease. Proc Nutr Soc 65:97-105

66. Davey Smith G, Ebrahim S 2003 'Mendelian randomization': can genetic epidemiology contribute to understanding environmental determinants of disease? Int Epidemiol 32:1-22

67. Sacerdote C, Guarrera S, Smith GD, Grioni S, Krogh V, Masala G, Mattiello A, Pall D, Panico S, Tumino R, Veglia F, Matullo G, Vineis P 2007 Lactase persistence and bitter taste response: instrumental variables and mendelian randomization in epidemiologic studies of dietary factors and cancer risk. Am J Epidemiol 166:576-581 